\title{
Impact of Powdered Activated Carbon and Anion Exchange Resin on Photocatalytic Treatment of Textile Wastewater
}

\author{
Preethi Grace Theva Neethi Dhas, Holger Gulyas, Ralf Otterpohl \\ Institute of Wastewater Management and Water Protection, Hamburg University of Technology, Hamburg, \\ Germany \\ Email: holli@tuhh.de
}

Received 9 February 2015; accepted 2 March 2015; published 5 March 2015

Copyright (C) 2015 by authors and Scientific Research Publishing Inc.

This work is licensed under the Creative Commons Attribution International License (CC BY).

http://creativecommons.org/licenses/by/4.0/

(c) (i) Open Access

\begin{abstract}
In order to clarify the impact of activated carbon and anion exchange resin on photocatalytic oxidation (PCO) of textile industry wastewater, $\mathrm{TiO}_{2}$-based PCO was investigated with aqueous solutions containing the reactive dye Reactive Blue 4 (RB4) and with a textile dye house effluent in the absence and in the presence of powdered activated carbon (PAC) and the anion exchange resin Lewatit MP 500. Addition of Lewatit improved RB4 removal to a larger extent than PAC addition. Contrasting to chloride and sulfate, hydrogen carbonate clearly inhibited PCO of RB4. However, the depression of dye removal by hydrogen carbonate was minute in the presence of Lewatit although the hydrogen carbonate concentration was not markedly decreased. Unfortunately, the beneficial effect of Lewatit addition on PCO nearly disappeared when the Lewatit/TiO ${ }_{2}$ mixture was reused three times. This was probably caused by oxidative damage of the resin. Color removal from the real dye house effluent during PCO was improved by Lewatit, but not by PAC. Contrastingly, PAC addition increased TOC removal by PCO from the real wastewater to some extent, while Lewatit had no impact. Sorbent addition does not lead to an acceptable area demand for solar PCO of the dye house effluent.
\end{abstract}

\section{Keywords}

Activated Carbon, Anion Exchange, Hybrid Process, Photocatalytic Oxidation, Textile Industry Effluent

\section{Introduction}

In 2011, the worldwide production of textile amounted to about 25,000 tons cotton fibers, nearly 50,000 tons

How to cite this paper: Dhas, P.G.T.N., Gulyas, H. and Otterpohl, R. (2015) Impact of Powdered Activated Carbon and Anion Exchange Resin on Photocatalytic Treatment of Textile Wastewater. Journal of Environmental Protection, 6, 191-203. http://dx.doi.org/10.4236/jep.2015.63020 
synthetic fibers, about 100 tons protein fibers and nearly 4500 tons cellulose fibers [1]. Textile industry causes large quantities of wastewaters as the production of one ton textile is accompanied by the generation of 50 to $250 \mathrm{~m}^{3}$ effluent [1]. Wastewaters are generated predominantly in the following processes of textile production: slashing/sizing, desizing, scouring, bleaching, mercerising, dyeing, printing, and finishing [1]. Characteristics of textile industry effluents are very different and depend on the kind of the manufactured textiles. Besides organic substances, the wastewaters contain also inorganic compounds such as sulfate (which has been determined in high concentrations) [1], chloride, carbonate, phosphate and heavy metals [2]. Presence of different heavy metals at concentrations $\leq 100 \mathrm{mg} / \mathrm{L}$ can be caused by metallized dyes. $\mathrm{Cr}$ can originate from acid dyes, $\mathrm{Cu}$ from direct dyes, and traces of $\mathrm{Hg}$ are present in different raw materials of textile processing [2]. Also organic dyes can exert toxic effects [3], and anaerobic metabolites of azo dyes represent potential carcinogens [4]. Thus, dyeing, printing and finishing were reported to generate wastewaters with high toxicity [5]. Moreover, raw textile wastewaters after dyeing and finishing often are characterised by intense color [5]. Mondal [6] identified dyes as those constituents of textile wastewater causing the largest difficulties in treatment. The concentration of dyes in textile industry effluents varies greatly with the type of dye used and the kind of dyeing process. Ghaly et al. [1] give 10 to $250 \mathrm{mg} / \mathrm{L}$ as a range of dye concentrations in dye house effluents.

Although aerobic biological treatment is generally feasible to remove organics from textile industry effluents [2], BOD/COD ratios of textile effluents are too low in many cases to operate biological treatment stages successfully [7]. Color removal by this process is ranked from low [2] [8] to insignificant-especially when azo dyes are used [5]. Partial color removal in biological treatment is mainly attributed to precipitation of insoluble dyes and biosorption of soluble dyes [2]. Toxicity of most of the commercial dyes causes problems in biological treatment of textile wastewater such as sludge bulking, sludge rising and inefficient floc formation [5].

As alternatives to biological treatment, adsorption, ion exchange, membrane processes and oxidative processes are feasible to remove acid, reactive, direct, mordant, metal complex as well as basic dyes. Coagulation, membrane processes and chemical oxidation processes are able to remove disperse, azoic, vat and sulphur dyes [2]. This listing shows that oxidation processes are versatile with respect to dye removal from textile wastewaters. However, chlorine and hydrogen peroxide have been evaluated as unsatisfactory oxidants in comparison to ozone for color removal from the effluent of an MBR treating textile wastewater [9]. Ozonation of biologically pretreated textile wastewater has been shown an efficient color removal technology [10]. However, Robinson et al. [11] mention cost as one of the major drawbacks with ozonation. Also advanced oxidation processes (AOPs) were tested for the treatment of textile dyeing effluents and found to be superior over coagulation [12].

Heterogeneous photocatalysis using the industrial mass product $\mathrm{TiO}_{2}$ was recognized as an AOP offering an important advantage over other existing oxidative technologies: It does not require the use of hazardous oxidative substances such as hydrogen peroxide or ozone. Moreover, $\mathrm{TiO}_{2}$ (which is ideally not consumed because it is used as a catalyst) is non-toxic, chemically stable as well as highly photocatalytically active and inexpensive [13]. Additionally, heterogeneous photocatalytic oxidation (PCO) can be powered by the sun, although there are several challenges to bring solar photocatalysis to technical application [14].

PCO with $\mathrm{TiO}_{2}$ as catalyst has been numerously investigated with simulated textile wastewaters which were prepared by dissolving different dyes in water. These investigations were subject of some review articles, e.g. by Ahmed et al. [15], Akpan and Hameed [3] and Khataee and Kasiri [16]. Rauf et al. [4] reviewed the photocatalytic degradation of azo dyes in the presence of $\mathrm{TiO}_{2}$ doped with transition metals. Alahiane et al. [17], Chebli et al. [18], and Kodom et al. [19] have tested PCO of dye solutions with $\mathrm{TiO}_{2}$ supported on carriers. Solar PCO of the azo dye Acid Orange 7 resulted in considerable color and TOC removal even in North Germany in October [20]. It was also found that the addition of activated carbon to solutions of dyes was beneficial for PCO [21] [22].

A less extent of research has been executed on PCO of real textile industry wastewaters, e.g. by Chun and Yizhong [23], Gebrati et al. [24], Gümüş and Akbal [25], Hussein [26], and Pekakis et al. [27]. In those experiments, specific energy consumption by UV lamps was between 270 and $4000 \mathrm{Wh} / \mathrm{L}$. In spite of this high power input, removal of COD and sometimes also of color was not complete.

Also solar PCO experiments were conducted with real textile wastewaters [26] [28] [29]. Although Hussein [26] optimistically concluded from his study that "heterogeneous photocatalytic processes under natural weathering conditions, in the presence of solar radiation show a promising degradation", other studies indicate high area demand for solar PCO of textile wastewaters [28] [30]. The most costly factor in solar PCO is the land requirement [28]. 
For making solar photocatalytic oxidation of textile wastewaters a viable process, enhancement of its efficiency is needed. As dyes were recently shown to be well adsorbed to anion exchange resins [31] [32] and also to anion exchange membranes [33], in this study $\mathrm{TiO}_{2}$-based PCO of model wastewaters containing Reactive Blue 4 (RB4) and also of a real wastewater was investigated in the presence and in the absence of the anion exchange resin Lewatit MP 500. It was evaluated whether the hybrid process of PCO and anion exchange causes increased PCO efficiency. This hybrid process was compared to another photocatalytic hybrid process: PCO/ powdered activated carbon (PAC). In the experiments with model wastewaters, also the impact of salts on the different PCO processes was investigated.

\section{Experimental Procedures}

\subsection{Textile Dye House Effluent}

A textile dye house effluent was transported for experiments from an Indian textile dyeing company. Typical characteristics of the wastewater as determined by the company in India were $1200 \mathrm{mg} / \mathrm{L} \mathrm{COD,} 180 \mathrm{mg} / \mathrm{L} \mathrm{BOD}_{5}$, a low turbidity, a light pink color, and lack of odor. The wastewater was reported to be alkaline (pH 11.7) with a total alkalinity of about $300 \mathrm{mg} \mathrm{CaCO}_{3} / \mathrm{L}$ and rather saline with a total dissolved solids concentration of around $5300 \mathrm{mg} / \mathrm{L}$ and an electric conductivity of $8.5 \mathrm{mmho} / \mathrm{cm}$. The predominant part of the salts was represented by chloride $(2000 \mathrm{~g} / \mathrm{L})$ and sulfate $(1300 \mathrm{mg} / \mathrm{L})$. After shipment, the samples were stored in the refrigerator at $4^{\circ} \mathrm{C}$ until further analysis and PCO experiments.

\subsection{Model Wastewaters}

Different model wastewaters were prepared by dissolving $100 \mathrm{mg} / \mathrm{L}$ Reactive Blue 4 (RB4) dye (Sigma-Aldrich Taufkirchen, Germany; see Figure 1 for structure) in the following liquids: deionised water, deionised water containing $0.084 \mathrm{~mol} / \mathrm{L} \mathrm{NaCl}$ and $0.010 \mathrm{~mol} / \mathrm{L} \mathrm{Na}_{2} \mathrm{SO}_{4}$, and tap water also additionally containing $0.084 \mathrm{~mol} / \mathrm{L}$ $\mathrm{NaCl}$ and $0.010 \mathrm{~mol} / \mathrm{L} \mathrm{Na}_{2} \mathrm{SO}_{4}$. NaCl and $\mathrm{Na}_{2} \mathrm{SO}_{4}$ were purchased in analytical grade from Merck (Darmstadt, Germany).

\subsection{Adsorption to Sorbents}

The following two sorbents were tested: first, PAC (analytical grade, Merck Eurolab, Darmstadt, Germany, article no. 102186), which exhibits a low ash content $(<1 \%)$, a BET surface of $775 \mathrm{~m}^{2} / \mathrm{g}$ and an average particle size of about $60 \mu \mathrm{m}$, and second, Lewatit Monoplus MP 500 (Bayer AG, Leverkusen, Germany) in the chloride form, a strongly basic, macroporous anion exchange resin with beads of uniform size $(0.62 \mathrm{~mm})$ based on a styrene-divinylbenzene copolymer. The anion exchange resin was not further prepared by any washing with hydroxide solution, i.e. it was used in the original $\mathrm{Cl}$ form. The sorbents were added to a solution of $100 \mathrm{mg} / \mathrm{L} \mathrm{RB} 4$ in tap water spiked with $0.01 \mathrm{~mol} / \mathrm{L} \mathrm{Na}_{2} \mathrm{SO}_{4}$ and $0.084 \mathrm{~mol} / \mathrm{L} \mathrm{NaCl}$ yielding sorbent concentrations of 100,300 , 500 and $1000 \mathrm{mg} / \mathrm{L}$. These suspensions were agitated on a rotational shaker at 150 rounds per minute and $20^{\circ} \mathrm{C}$ for 72 hours. The supernatants were filtered over membrane filters (Magna Nylon, pore width $0.45 \mu \mathrm{m}$, Carl Roth GmbH, Karlsruhe, Germany) and the filtrates analyzed for RB4 concentrations.

\subsection{Photolysis and PCO of Model Wastewaters}

Batches of one liter model wastewater without (photolysis) and with $0.1 \mathrm{~g} / \mathrm{L} \mathrm{TiO}_{2}$ photocatalyst (Aeroxide "P25”, Evonik Industries AG, Hanau-Wolfgang, Germany) were stirred (magnetic stirrer bar length 7 cm; stirrer<smiles></smiles>

Figure 1. Structure of reactive blue 4 . 
speed 300 rounds per minute) in slim $2 \mathrm{~L}$ beakers (inner diameter $10.8 \mathrm{~cm}$ ) in the absence and presence of co-adsorbents $(0.1 \mathrm{~g} / \mathrm{L}$ Merck PAC or $0.05 \mathrm{~g} / \mathrm{L}$ or $0.1 \mathrm{~g} / \mathrm{L}$ Lewatit anion exchange resin) for at least 42 hours without UV irradiation in order to establish adsorption equilibrium. The solutions (photolysis) and suspensions (PCO) were then UV-A irradiated with face tanners (Philips HB 172; emission maximum at $351 \mathrm{~nm}$ ) under stirring. The UV lamps were installed at a distance of $20 \mathrm{~cm}$ above the liquid surface resulting in a UV intensity of $25 \mathrm{~W} / \mathrm{m}^{2}$ measured with a Pyranometer CM6B (Kipp \& Zonen, Delft, Netherlands). During UV irradiation, the temperatures of the reactors were between $21^{\circ} \mathrm{C}$ and $25^{\circ} \mathrm{C}$.

Evaporation loss during UV irradiation was determined by weighing the reactors before and after each sampling and replenished by deionized water before each sampling. Samples of $50 \mathrm{~mL}$ were taken at different time intervals, transferred to $100 \mathrm{~mL}$ bottles and allowed to settle overnight. The supernatants were centrifuged (Hettich EBA 3 S, 4000 rounds per minute) and centrifugation supernatants were filtered through folded paper filters prior to TOC and photometric analysis.

\subsection{Photocatalyst and Sorbents Reuse}

A series of experiments were conducted with the hydrogen carbonate-containing model wastewater $(100 \mathrm{mg} / \mathrm{L}$ RB4 dye in tap water spiked with $0.084 \mathrm{~mol} / \mathrm{L} \mathrm{NaCl}$ and $0.010 \mathrm{~mol} / \mathrm{L} \mathrm{Na}_{2} \mathrm{SO}_{4}$ ) after preparing four different suspensions with the following solids in the model wastewater: first, $0.1 \mathrm{~g} / \mathrm{L} \mathrm{TiO}_{2}$, second, $0.05 \mathrm{~g} / \mathrm{L}$ Lewatit resin, third, $0.1 \mathrm{~g} / \mathrm{L} \mathrm{TiO}_{2}$ mixed with $0.1 \mathrm{~g} / \mathrm{L}$ PAC and fourth, $0.1 \mathrm{~g} / \mathrm{L} \mathrm{TiO}_{2}$ mixed with $0.05 \mathrm{~g} / \mathrm{L}$ Lewatit resin. The suspensions were UV-irradiated for $48 \mathrm{~h}$ and the solids were separated from the liquid phase by centrifugation (30 min at 4000 rounds per minute in a Heraeus Multifuge X3, Thermo Scientific) after irradiation was accomplished and reused four times in further PCO cycles with fresh model wastewater. For this purpose, the centrifuged solids were subsequently mixed with $1 \mathrm{~L}$ fresh model wastewater and the suspensions irradiated within the next cycle. Samples were collected before addition of catalyst and/or adsorbent and after each $48 \mathrm{~h} \mathrm{UV} \mathrm{ir-}$ radiation cycle subsequent to separation of the solids from the liquid phase. Irradiated samples were membrane-filtered ( $0.45 \mu \mathrm{m}$ pore size) prior to analyses. All samples were analysed for TOC and dye concentration.

\subsection{PCO of Real Textile Wastewater}

PCO experiments with the real wastewater were performed with an increased amount of catalyst $\left(1 \mathrm{~g} / \mathrm{L} \mathrm{TiO}_{2}\right)$ without and with co-adsorbent $(0.5 \mathrm{~g} / \mathrm{L}$ PAC or $0.5 \mathrm{~g} / \mathrm{L}$ Lewatit) due to the higher TOC concentration in comparison to the model wastewaters. The $\mathrm{pH}$ in the reactors was measured once at the beginning and after completion of irradiation. The other conditions were similar to experiments with model wastewaters. Samples were analysed for TOC and color. Experiments with TOC analysis were done in duplicates.

\subsection{Analysis}

TOC was measured according to the German standard method [34] using a TOC analyser multi-N/C 3000 (Analytik Jena, Jena, Germany). Total inorganic carbon (TIC) and total nitrogen were analysed with the same instrument. Color was determined with a double beam photometer (V-550, Jasco GmbH, Germany) using plastic cuvettes for the model wastewater and quartz glass cuvettes (Suprasil, Hellma GmbH, Müllheim, Germany) for the real wastewater. RB4 concentrations were analysed photometrically by means of calibration standards with known RB4 concentrations. The spectrum of each model wastewater sample and calibration solution was recorded from 800 to $400 \mathrm{~nm}$. The height of the absorption maximum at $599 \mathrm{~nm}$ was corrected by subtracting the height of a valley-to-valley baseline from the height of the absorbance maximum. This absorbance difference was linearly related to the dye concentration. In case of the real textile dye effluent, no absorption maximum was observed in the visible range. Absorbance at $420 \mathrm{~nm}$ was therefore used as surrogate for color of the wastewater. A WTW SenTix41 probe connected to a Multi 3401 pH meter (WTW, Weilheim, Germany) was used for $\mathrm{pH}$ recording.

\section{Results and Discussion}

\subsection{Adsorption of RB4 from Model Wastewaters}

Pure PAC and Lewatit (without being accompanied by $\mathrm{TiO}_{2}$ ) adsorbed $\mathrm{RB} 4$ from the model wastewater in a tap water matrix additionally containing inorganic salts (Figure 2). The mechanism of RB4 removal by anion ex- 


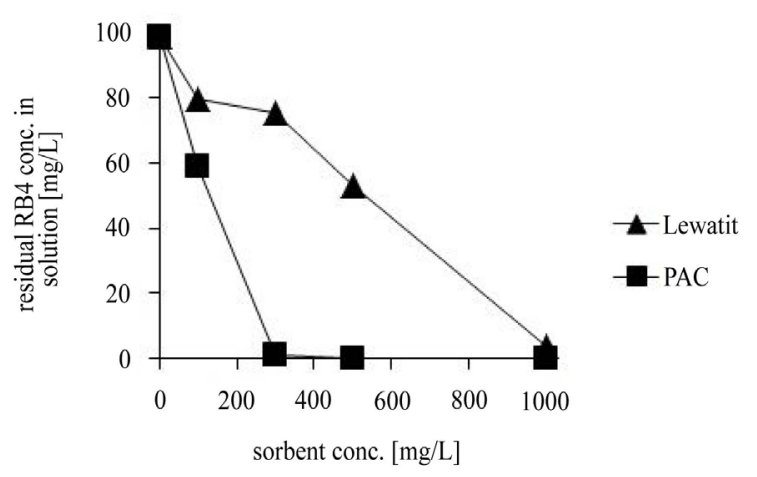

Figure 2. Adsorptive RB4 removal by Lewatit and PAC recorded at $20^{\circ} \mathrm{C}$ with a $100 \mathrm{mg} / \mathrm{L} \mathrm{RB} 4$ solution in tap water spiked with $0.084 \mathrm{~mol} \mathrm{NaCl} / \mathrm{L}$ and $0.01 \mathrm{~mol} \mathrm{Na}_{2} \mathrm{SO}_{4} / \mathrm{L}(\mathrm{pH} 7.4)$.

change can be explained by the two sulfonic acid functional groups contained in the molecule (see Figure 1) which are converted to anionic sulfonate groups by dissociation of protons. Nevertheless, Lewatit turned out to be a less efficient adsorbent for RB4 than PAC (see_Figure 2). Karcher et al. [31] have investigated the sorption of another reactive dye, Reactive Black 5 (2 g/L), which contains four sulfonate groups contrasting to only two in RB4, to a different anion exchange resin (weak basic MP62) the concentration of which was $2 \mathrm{~g} / \mathrm{L}$. They found an increased removal of the reactive dye from the aqueous phase when increasing $\mathrm{pH}$ from 4.5 ( $40 \%$ removal) to 7.5 ( $>50 \%$ removal). Increase of $\mathrm{pH}$ above 8 resulted in even higher removal efficiencies of Reactive Black 5 by the anion exchange resin MP62 [31]. The results in the study of Karcher et al. [31] were better than the $20 \%$ removal of RB4 from $100 \mathrm{mg} / \mathrm{L}$ solutions with a Lewatit concentration of $100 \mathrm{mg} / \mathrm{L}$ at pH 7.4 as shown in Figure 2.

Figure 2 shows that with $50 \mathrm{mg} / \mathrm{L}$ PAC, a reduction in RB4 concentration of about 20\% was achieved. This was contrasting to a 73\% RB4 removal during stirring of the same model wastewater with $100 \mathrm{mg} / \mathrm{L} \mathrm{TiO}_{2}$ and $50 \mathrm{mg} / \mathrm{L}$ PAC even when considering a 14.7\% RB4 removal by adsorption to $\mathrm{TiO}_{2}$ (Table 1). There was also a substantial decrease of RB4 concentration by nearly 70\% subsequent to stirring the suspensions without UV when PAC was replaced by Lewatit (Table 1). This removal by adsorption to a mixture of $\mathrm{TiO}_{2}$ and Lewatit also cannot be explained by summing up the $14.7 \%$ adsorption to $\mathrm{TiO}_{2}$ (Table 1 ) and about $10 \%$ adsorption to pure Lewatit (Figure 2).

When a higher concentration $(100 \mathrm{mg} / \mathrm{L})$ of Lewatit was added to the $\mathrm{TiO}_{2}$ suspension in the $\mathrm{RB} 4$ matrix in deionized water spiked with $\mathrm{NaCl}$ and $\mathrm{Na}_{2} \mathrm{SO}_{4}$, there was nearly no color detectable even without UV irradiation (Table 1). Overall, the Lewatit/ $/ \mathrm{TiO}_{2}$ mixture is a promising adsorbent for RB4. As another advantage of adding Lewatit to PCO, better settling of the $\mathrm{TiO}_{2}$ nanoparticles along with the resin was observed.

It was interesting that the inorganic matrix of the model wastewater did not markedly affect the adsorption of RB4 to $\mathrm{TiO}_{2}$ and to $\mathrm{TiO}_{2} /$ Lewatit mixture, while adsorption to the $\mathrm{TiO}_{2} / \mathrm{PAC}$ was larger in the saline matrices than in the deionized water matrix.

\subsection{Photolysis and PCO of Model Wastewaters}

Figure 3 shows concentrations of RB4 and TOC in different RB4 solutions in different matrices during UV-A illumination. RB4 was only slightly susceptible to photolysis and there was no clear effect of the inorganic wastewater matrix on photolysis (Figure 3(a)). No mineralization took place during UV-A irradiation (Figure 3(b)).

Stirring $\mathrm{TiO}_{2}$ with the different model wastewaters for $<42 \mathrm{~h}$ without UV-A irradiation resulted in about $15 \%$ removal of RB4 by adsorption to the photocatalyst (Table 1). UV-A illumination of the suspensions led to a further decrease in RB4 concentration (Figure 4(a)). Chloride and sulfate addition to deionized water did not markedly decrease PCO efficiency (compare curves "salts/DI water" and "DI water" in Figure 4(a)). It can thus be concluded that chloride and sulfate were not massively depressing RB4 PCO efficiency, although inorganic salts have been discussed by many authors to deteriorate the PCO process [35]-[39]. Alahiane et al. [17] who investigated the impact of different inorganic salts on photocatalytic oxidation of Reactive Yellow 145 by 
Table 1. Removal of RB4 by adsorption from the tested model wastewaters to $\mathrm{TiO}_{2}(100 \mathrm{mg} / \mathrm{L})$ and to mixtures of $\mathrm{TiO}_{2}$ with PAC or Lewatit during the stirring period of $>42 \mathrm{~h}$ without UV prior to PCO (DI water = deionized water).

\begin{tabular}{|c|c|c|c|}
\hline & \multicolumn{3}{|c|}{ RB4 removal in the dark [\%] } \\
\hline & DI water & Salts/DI water & Salts/tap water \\
\hline $\mathrm{TiO}_{2}$ & 15.4 & 14.2 & 14.7 \\
\hline $\mathrm{TiO}_{2}+50 \mathrm{mg} / \mathrm{L}$ PAC & 36.2 & 79.0 & 73.0 \\
\hline $\mathrm{TiO}_{2}+50$ mg/L Lewatit & 68.6 & 74.8 & 68.8 \\
\hline $\mathrm{TiO}_{2}+100 \mathrm{mg} / \mathrm{L}$ Lewatit & - & 98.8 & - \\
\hline
\end{tabular}
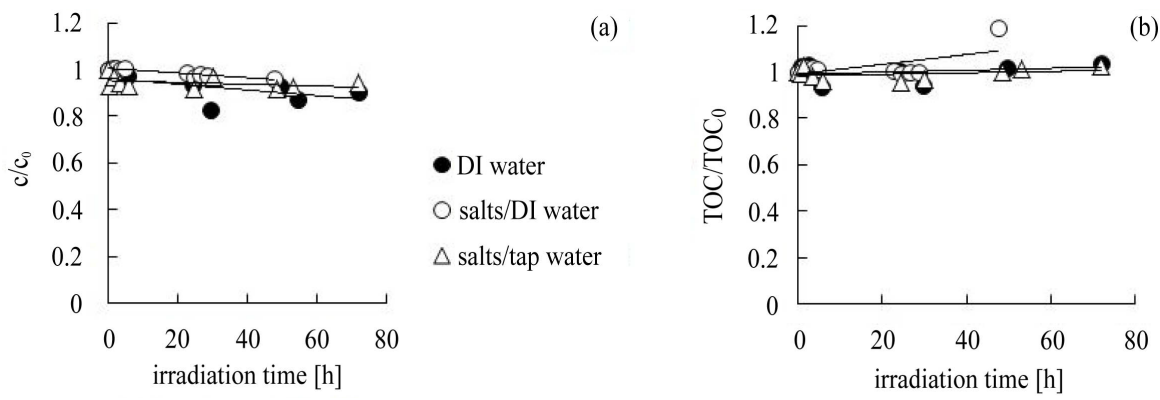

Figure 3. Normalized RB4 (a) and TOC concentrations (b) of $100 \mathrm{mg} / \mathrm{L}$ RB4 solutions in deionized water, in a deionized water matrix containing additionally $0.084 \mathrm{~mol} / \mathrm{L} \mathrm{NaCl}$ and $0.01 \mathrm{~mol} / \mathrm{L} \mathrm{Na}_{2} \mathrm{SO}_{4}$ and in a tap water matrix containing additionally $0.084 \mathrm{~mol} / \mathrm{L} \mathrm{NaCl}$ and $0.01 \mathrm{~mol} / \mathrm{L} \mathrm{Na}_{2} \mathrm{SO}_{4}$ during photolysis.
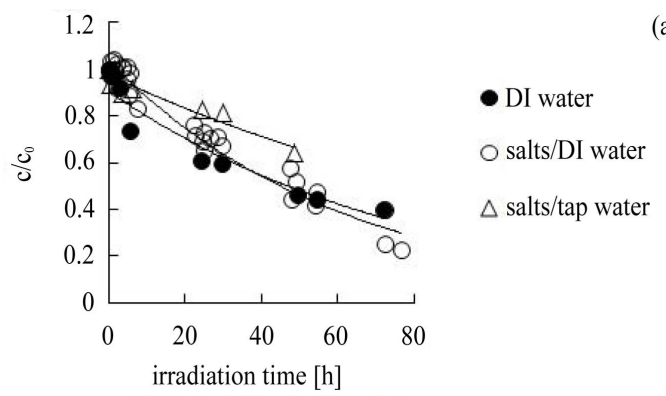

(a)

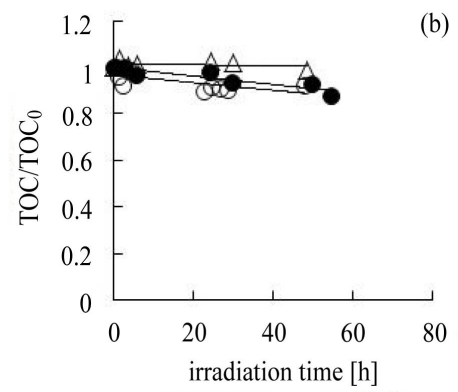

Figure 4. Normalized RB4 (a) and TOC concentrations (b) of $100 \mathrm{mg} / \mathrm{L}$ RB4 solutions in deionized water, in a deionized water matrix containing additionally $0.084 \mathrm{~mol} / \mathrm{L} \mathrm{NaCl}$ and $0.01 \mathrm{~mol} / \mathrm{L} \mathrm{Na}_{2} \mathrm{SO}_{4}$ and in tap water containing additionally $0.084 \mathrm{~mol} / \mathrm{L} \mathrm{NaCl}$ and $0.01 \mathrm{~mol} / \mathrm{L}$ $\mathrm{Na}_{2} \mathrm{SO}_{4}$ during PCO without adsorbents.

$\mathrm{TiO}_{2}$-coated natural and synthetic non-woven filters found even an increase of PCO efficiency by chloride and sulfate.

In order to simulate the real textile dye house effluent which contains considerable amounts of hydrogen carbonate as indicated by the total alkalinity of about $300 \mathrm{mg} \mathrm{CaCO} / \mathrm{L}$, RB4 solutions were also prepared in tap water spiked with $\mathrm{NaCl}$ and $\mathrm{Na}_{2} \mathrm{SO}_{4}$ in similar concentrations as in the real textile wastewater. $\mathrm{RB} 4$ removal by PCO in the tap water matrix with salts was slightly less efficient than in the deionized water matrix (open triangles in Figure 4(a)) which can be explained by the radical scavenging effect of hydrogen carbonate contained in the tap water which exhibited a TIC concentration of $22 \mathrm{mg} / \mathrm{L}$ (equivalent to $112 \mathrm{mg} / \mathrm{L} \quad \mathrm{HCO}_{3}^{-}$). Alkalinity has been recently shown to have an inhibitory effect on PCO [30].

The $\mathrm{pH}$ of the $\mathrm{TiO}_{2}$ suspensions in the deionised water matrix with $\mathrm{NaCl}$ and $\mathrm{Na}_{2} \mathrm{SO}_{4}$ (which did not contain hydrogen carbonate) was 4.8 , while it was 7.4 in the tap water matrix with $\mathrm{NaCl}$ and $\mathrm{Na}_{2} \mathrm{SO}_{4}$. Therefore, also the $\mathrm{pH}$ might have influenced the PCO efficiency. Kodom et al. [19] ascertained that photocatalysis of Reactive Black 5 with $\mathrm{TiO}_{2}$ coated on paper showed the highest efficiency at $\mathrm{pH} 3$, while the activity was less at $\mathrm{pH} 7$. This was explained by predominance of negatively charged surface groups on the photocatalyst surface at $\mathrm{pH} 7$ resulting in decreased adsorbability of the dye's sulfonate groups. Similarly, increased COD removal from a real 
textile industry effluent as well as increased decolorisation of an aqueous Remazol Red 133 solution were achieved by photocatalytic oxidation at $\mathrm{pH} 3$ in comparison to $\mathrm{pH} 9.5$ [25].

Demineralization of RB4 solutions by PCO was negligible (Figure 4(b)). In the presence of the radical scavenger hydrogen carbonate, nearly no mineralization took place within $50 \mathrm{~h} \mathrm{UV}$ irradiation in the presence of $\mathrm{TiO}_{2}$ (open triangles in Figure 4(b)).

In the presence of PAC, PCO of RB4 was clearly inhibited in the tap water matrix. According to [17], chloride and sulfate did not decrease the efficiency of decolorisation by PCO in the presence of PAC (Figure 5(a)). However, mineralisation in the PCO/PAC hybrid process was depressed by salts (open circles in Figure 5(b)). A comparison of Figure 4(a) to Figure 5(a) indicates that the addition of PAC promotes RB4 removal percentage by PCO. Also the mineralization of RB4 solutions in deionized water was enhanced by PAC addition (compare filled circles in Figure 4(b) to those in Figure 5(b)), but not in the salt-containing matrices. However, also for the salt-containing model wastewaters, the PAC/PCO hybrid process was beneficial, as PAC addition resulted in 70\% - 80\% adsorptive RB4 removal (Table 1).

The addition of the anion exchange resin Lewatit MP 500 to $\mathrm{TiO}_{2}$ was very promising for color removal from all tested model wastewaters, because besides good adsorptive removal of RB4 by $\mathrm{TiO}_{2} /$ Lewatit mixtures (Table 1), it also efficiently promoted the photocatalytic RB4 removal in all matrices (Figure 6(a)). It was surprising that PCO was even more efficient in the salt-containing model wastewaters. Obviously, addition of Lewatit was able to depress the radical-scavenging effect of hydrogen carbonate on decolorization (open triangles in Figure 6(a)) but not on mineralization (open triangles in Figure 6(b)). However, the larger slope of the curve for photocatalytic oxidation in the presence of Lewatit (Figure 6(a)) in comparison to the curve for mere PCO (Figure 4(a)) cannot be attributed to adsorptive removal of hydrogen carbonate by Lewatit, because Lewatit addition decreased TIC only marginally from $22 \mathrm{mg} / \mathrm{L}$ to $18.7 \mathrm{mg} / \mathrm{L}$ measured at the end of the PCO/Lewatit hybrid experiment (data not shown).

\subsection{Multiple Reuse of Photocatalyst and Sorbents}

Long-term dye removal capacity of Lewatit and different photocatalytic procedures can be visualised when the solids are reused several times. Figure 7 shows residual dye (a) and TOC (b) concentrations (related to the concentrations of the model wastewater before addition of the solids) after $48 \mathrm{~h} \mathrm{UV}$ irradiation of the salt-containing model wastewater (100 mg/L RB4, $0.084 \mathrm{~mol} / \mathrm{L} \mathrm{NaCl}$ and $0.01 \mathrm{~mol} / \mathrm{L} \mathrm{Na}_{2} \mathrm{SO}_{4}$ in a tap water matrix) in the presence of $\mathrm{TiO}_{2}, \mathrm{TiO}_{2} / \mathrm{PAC}$ and $\mathrm{TiO}_{2} /$ Lewatit which had been recycled by centrifugation subsequent to each irradiation cycle and added to a fresh batch of model wastewater for another illumination cycle. The results from photometric measurements (Figure 7(a)) and from TOC analyses (Figure 7(b)) correlated to some extent.

In Figure 7(a), it can be seen that the PCO/Lewatit hybrid process shows a similar RB4 removal (42\%) as the PCO/PAC process when the solids were used for the first time (solids reuse cycle 0 ). PCO (21\% RB4 removal) was less efficient than the hybrid processes, because the latter ones included RB4 adsorption to PAC or Lewatit. The major difference to the experiments described in Section 3.2 was the lack of pre-agitation of the suspensions prior to UV illumination. From Table 1 and Figures 4(a)-6(a), it can be concluded that the investigated processes with stirring of suspensions prior to UV irradiation showed the following rank order for RB4 removal from the model wastewater in the tap water matrix spiked with chloride and sulfate: PCO/Lewatit (98\% RB4 removal) > PCO/PAC (81\% RB4 removal) > PCO (45\% RB4 removal). So, the RB4 removal in the experiments with preagitation prior to UV irradiation was definitely larger.

In the PCO/PAC hybrid process (crosses in Figure 7(a) and Figure 7(b)), dye and TOC removal efficiency were markedly decreased from about $40 \%$ (when using fresh solids) in subsequent cycles of $\mathrm{TiO}_{2} / \mathrm{PAC}$ reuse reaching the same low level as PCO without PAC (open circles) in reuse cycles 2, 3 and 4. This indicates that the PAC was not regenerated during the preselected $48 \mathrm{~h} \mathrm{PCO} \mathrm{period} \mathrm{and} \mathrm{that} \mathrm{much} \mathrm{longer} \mathrm{UV} \mathrm{irradiation} \mathrm{times}$ would be needed for the photocatalytic PAC regeneration. In a recent study about the PCO/PAC hybrid process for TOC removal from biologically pretreated greywater [40], the TOC subsequent to UV irradiation also increased from one $\mathrm{TiO}_{2} / \mathrm{PAC}$ reuse cycle to the next. However, the initial TOC of the pretreated grey water was only half as much as that of the model wastewater used in this study, and the PCO/PAC hybrid process for grey water treatment was more efficient than mere PCO even after several reuse cycles.

The Lewatit suspension without $\mathrm{TiO}_{2}$ (open triangles in Figure 7) was not exposed to UV light, but only stirred for the same period as the other suspensions were irradiated for. When the Lewatit concentration was 50 

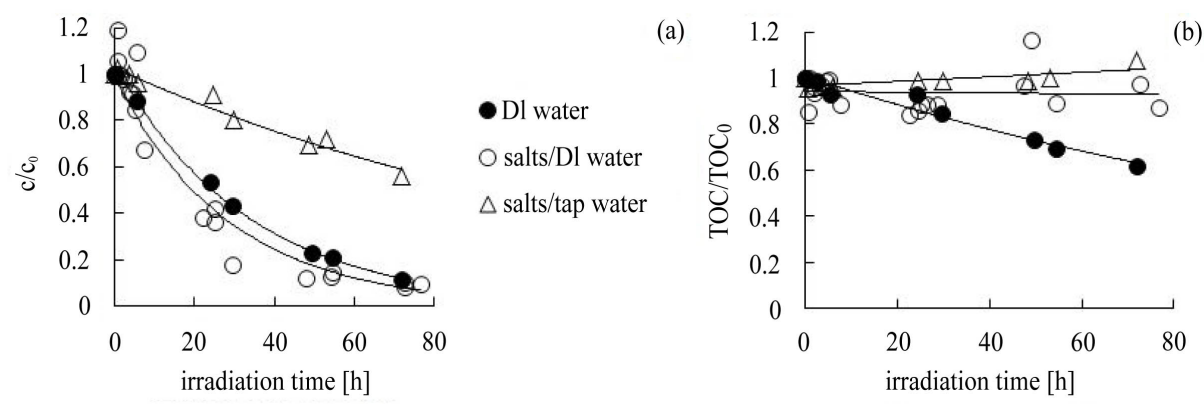

(b)

Figure 5. Normalized RB4 (a) and TOC concentrations (b) of $100 \mathrm{mg} / \mathrm{L}$ RB4 solutions in deionized water, in a deionized water matrix containing additionally $0.084 \mathrm{~mol} / \mathrm{L} \mathrm{NaCl}$ and $0.01 \mathrm{~mol} / \mathrm{L} \mathrm{Na}_{2} \mathrm{SO}_{4}$ and in tap water containing additionally $0.084 \mathrm{~mol} / \mathrm{L} \mathrm{NaCl}$ and $0.01 \mathrm{~mol} / \mathrm{L}$ $\mathrm{Na}_{2} \mathrm{SO}_{4}$ during PCO in the presence of $100 \mathrm{mg} / \mathrm{L} \mathrm{PAC}$.
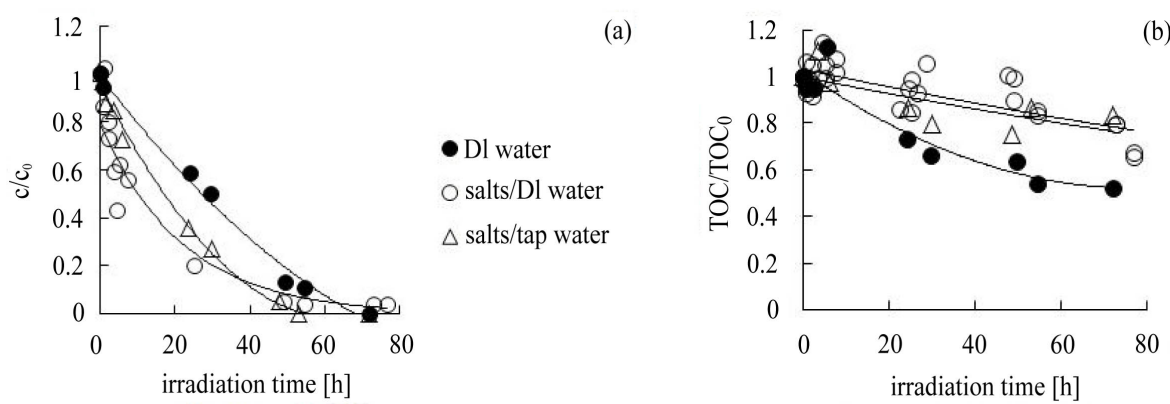

Figure 6. Normalized RB4 (a) and TOC concentrations (b) of 100 mg/L RB4 solutions in deionized water, in a deionized water matrix containing additionally $0.084 \mathrm{~mol} / \mathrm{L} \mathrm{NaCl}$ and $0.01 \mathrm{~mol} / \mathrm{L} \mathrm{Na}_{2} \mathrm{SO}_{4}$ and in tap water containing additionally $0.084 \mathrm{~mol} / \mathrm{L} \mathrm{NaCl}$ and $0.01 \mathrm{~mol} / \mathrm{L}$ $\mathrm{Na}_{2} \mathrm{SO}_{4}$ during PCO in the presence of $50 \mathrm{mg} / \mathrm{L}$ Lewatit.
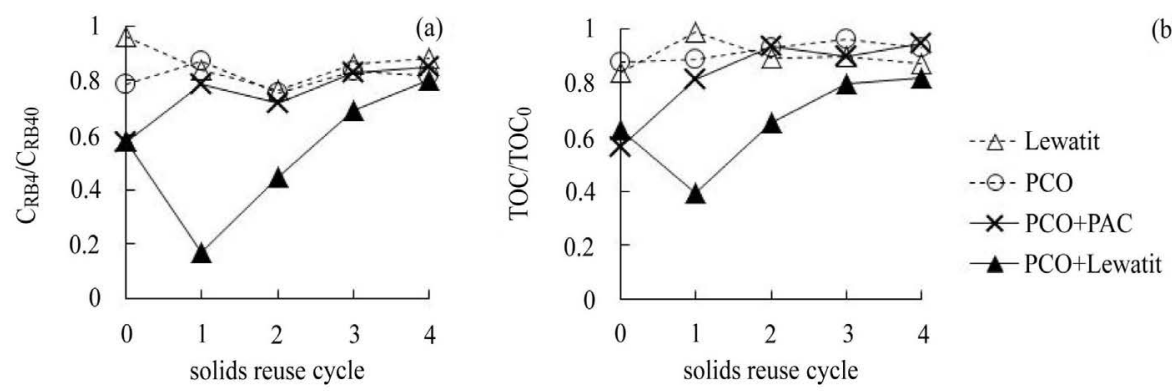

(b)

Figure 7. Normalized RB4 (a) and TOC (b) concentrations of salt-containing model wastewater $\left(100 \mathrm{mg} / \mathrm{L} \mathrm{RB} 4,0.084 \mathrm{~mol} / \mathrm{L} \mathrm{NaCl}\right.$ and $0.01 \mathrm{~mol} / \mathrm{L} \mathrm{Na}_{2} \mathrm{SO}_{4}$ in tap water) subsequent to $48 \mathrm{~h}$ treatment (PCO, PCO/PAC, PCO/Lewatit and stirring with $50 \mathrm{mg} / \mathrm{L}$ Lewatit without UV) within 5 cycles of use of the different solids.

$\mathrm{mg} / \mathrm{L}$, the anion exchange resin was obviously not completely loaded with RB4, because there was a reduction of dye and TOC concentration (approximately 10\% - 20\%) even in Lewatit reuse cycles 1 to 4 (open triangles in Figure 7) indicating that the adsorption capacity of the Lewatit was not yet completely expired even in the fourth reuse cycle. However, the fresh Lewatit (which had not been pretreated prior to use) showed only a marginal dye removal (Figure 7(a)). This is according to poor RB4 adsorption to $50 \mathrm{mg} / \mathrm{L}$ Lewatit as displayed in Figure 2. However, it is in contradiction to very good RB4 adsorption from the same model wastewater to Lewatit when $\mathrm{TiO}_{2}$ was added as shown in Table 1 . In the suspension containing the Lewatit/ $\mathrm{TiO}_{2}$ mixture either some photocatalytic removal of RB4 was caused in the pre-irradiation period by lighting in the laboratory, or the addition of $\mathrm{TiO}_{2}$ improved RB4 adsorption to Lewatit by effects which currently cannot be explained.

The Lewatit/PCO hybrid process with fresh solids (filled triangles in Figure 7(a) and Figure 7(b)) caused a 
dye removal of $42 \%$. This was much lower than after $48 \mathrm{~h} \mathrm{UV}$ irradiation in the experiment with pre-agitation in the dark displayed in Figure 3(c). A possible explanation for this contradiction is that adsorption to Lewatit was less efficient in the experiments on $\mathrm{TiO}_{2} /$ Lewatit reuse, because there was no stirring of the suspensions prior to the PCO period without UV irradiation for at least 42 hours. In contrast to the cycle with fresh Lewatit, nearly all dye was removed in the PCO/Lewatit hybrid process when the Lewatit/ $\mathrm{TiO}_{2}$ was reused for the first time. Unfortunately, in subsequent reuse cycles of the $\mathrm{TiO}_{2} /$ Lewatit mixture, the dye removal efficiency was massively reduced. In reuse cycle 4 it was reduced to the efficiency of the PCO process without co-adsorbent. This reduction in efficiency can be explained by progressing oxidative damage of the organic anion exchange resin within several solids reuse cycles or by insufficient photocatalytic regeneration of the Lewatit. This indicates that the Lewatit/PCO hybrid process - in spite of large decoloration efficiency when using $\mathrm{TiO}_{2} /$ Lewatit as fresh material or reusing it only once-is not recommendable because fresh resin has to be added at least after two to three reuse cycles.

Improvement of TOC removal from solids reuse cycle 0 to 1 in the PCO/Lewatit hybrid process (filled triangles in Figure 7(b)) can be explained as follows: In "solids reuse cycle 0", Lewatit was used without prior washing. A fishy smell indicated its content of amine from production of the anion exchange resin. This amount of amine probably caused some additional TOC. In the first reuse cycle, there was no more amine present on the Lewatit because it was washed to the liquid phase in the prior cycle. This might have resulted in a higher TOC removal in reuse cycle no. 1 . However, this is no explanation for improved RB4 removal by the reused $\mathrm{TiO}_{2} /$ Lewatit mixture during UV irradiation (filled triangles in Figure 7(a)).

\subsection{PCO of Real Textile Dye House Effluent}

The textile effluent had to be transported from India to Germany and hence the chemical characteristics of the effluent might have changed during transportation. It took four days for the samples to reach destination. The parameters of the wastewater measured in the laboratory in Hamburg are shown in Table 2. While the fresh original wastewater was reported to be odourless, it exhibited some fishy smell when it was used for the experiments. Additionally it was observed that the wastewater caused eye irritation during experimentation. Fishy smell and eye irritation may be referred to the generation of anilines from residual azo dyes during anaerobic storage of the wastewater sample. Both phenomena were no longer realized when the PCO experiments were accomplished. Also the color of the wastewater was no longer light pink as described by the company, but brown when it arrived at Hamburg (Table 2). This might also be a consequence of azo dye decay. The TOC concentration of $765 \mathrm{mg} / \mathrm{L}$ classifies the wastewater as suitable for being treated by an advanced oxidation process. However, it is in a relatively high range for this class of processes.

An absorbance maximum in the visible range could not be established from the spectrum recorded with the real textile wastewater (Figure 8). Only a small part of the major absorption band of the wastewater was in the visible range $>400 \mathrm{~nm}$. However, this was responsible for the brown color of the effluent. Decoloration was thus quantified by means of the absorbance at $420 \mathrm{~nm}$.

Experiments on adsorption of the wastewater organics to PAC, Lewatit and $\mathrm{TiO}_{2}$ (data not shown) indicated the possibility of applying higher concentrations of photocatalyst $(1 \mathrm{~g} / \mathrm{L})$ and co-adsorbent $(0.5 \mathrm{~g} / \mathrm{L})$ for the real wastewater still resulting in detectable color and TOC concentrations after contact of the wastewater with the solids. Because of residual organics being present after adsorption, color and TOC removal could be quantified in subsequent photocatalysis.

The $\mathrm{pH}$ was reduced from 12.4 in the beginning to around 9 at the end of the PCO experiments. This decrease in $\mathrm{pH}$ may be caused by degradation of anilines and is in accordance with the disappearance of the fishy smell after accomplishing PCO experiments.

Figure 9(a) shows that $\mathrm{TiO}_{2}$ and the $\mathrm{TiO}_{2} / \mathrm{PAC}$ mixture did not adsorb the colored substances from the real wastewater, whereas the $\mathrm{TiO}_{2} /$ Lewatit mixture even without UV irradiation well removed dye molecules absorbing light at $420 \mathrm{~nm}$. The mechanism behind the dye sorption cannot be explained, since the textile effluent probably contains many different dyes in small concentrations. It might be assumed that most of the residual dyes were reactive dyes, because those were used for dyeing cotton according to company information. At least, the efficient decoloration by Lewatit indicates that the color of the wastewater was mainly due to anionic substances. Probably, the residual dyes also contained sulfonate groups. Photocatalytic oxidation itself and also thePCO/PAC hybrid process were not that efficient for color removal. However, PCO could add some color re- 
Table 2. Real textile dye house effluent parameters.

\begin{tabular}{cc}
\hline Parameters & Values \\
\hline $\mathrm{pH}$ & 12.4 \\
Color & Brown \\
Odour & Fishy \\
TOC $(\mathrm{mg} / \mathrm{L})$ & 765 \\
Total nitrogen $(\mathrm{mg} / \mathrm{L})$ & 27.8 \\
TIC $(\mathrm{mg} / \mathrm{L})$ & 170 \\
\hline
\end{tabular}

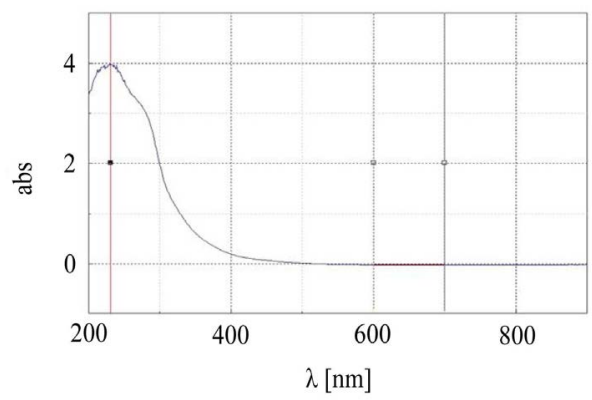

Figure 8. Absorption spectrum of the real textile dye house effluent.
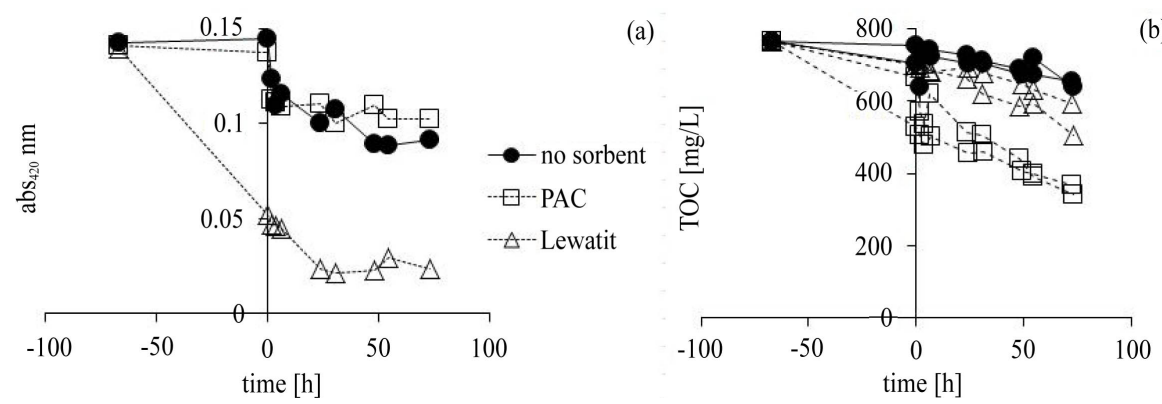

(b)

Figure 9. Removal of absorbance at $420 \mathrm{~nm}$ (a) and TOC (b) from real textile wastewater by PCO with $1 \mathrm{~g} / \mathrm{L} \mathrm{TiO}_{2}$ without and with additional sorbents ( $0.5 \mathrm{~g} / \mathrm{L}$ PAC or $0.5 \mathrm{~g} / \mathrm{L}$ Lewatit); negative time axis represents stirring of the suspensions without UV irradiation.

moval subsequent to Lewatit adsorption. Overall, the adsorption to Lewatit with additional PCO resulted in a color removal of about $80 \%$.

PCO treatment without the addition of sorbents did not show efficient mineralisation (Figure 9(b)). The contact of the real wastewater with Lewatit/ $\mathrm{TiO}_{2}$ without UV illumination contributed only to a small TOC removal (about 8\%). Photocatalytic TOC removal was not increased to a large extent by the addition of $0.5 \mathrm{~g} / \mathrm{L}$ of the coadsorbent Lewatit. The Lewatit/PCO hybrid process led to a TOC removal of only $22 \%$ to $34 \%$.

Adsorption to $\mathrm{PAC} / \mathrm{TiO}_{2}$ without UV removed $13 \%$ - 30\% of TOC with high data variation in duplicate experiments. At the end of the irradiation period, $52 \%-55 \%$ of TOC were removed by the PCO/PAC hybrid process. The PCO process in the presence of PAC showed a higher TOC removal than in the presence of Lewatit or in the absence of adsorbents, although the addition of PAC is expected to absorb UV photons making the process less efficient. A possible explanation of this contradiction might be the adsorption of wastewater constituents inhibiting the PCO process to PAC but not to Lewatit. On the other hand, Lewatit well adsorbed the colored substances.

An important aspect for process implementation is the energy requirement for PCO. The UV dose, $\mathrm{Q}_{\mathrm{UV}}$, introduced into the reactor can be calculated by Equation (1).

$$
\mathrm{Q}_{\mathrm{UV}}=\frac{\mathrm{I} \cdot \mathrm{A} \cdot \mathrm{t}}{\mathrm{V}_{\mathrm{L}}}
$$


where $\mathrm{I}$ is the $\mathrm{UV}$ intensity in $\mathrm{W} / \mathrm{m}^{2}$, A is the liquid surface area in $\mathrm{m}^{2}$, $\mathrm{t}$ is the irradiation time in $\mathrm{h}$ and $\mathrm{V}_{\mathrm{L}}$ is the volume of wastewater in the reactor in $\mathrm{L}$. Considering the reactor content of $1 \mathrm{~L}$, an inner diameter of the reactor of $10.8 \mathrm{~cm}$, a UV intensity of $25 \mathrm{~W} / \mathrm{m}^{2}$, and an irradiation time of $70 \mathrm{~h}$, a UV dose of $16.5 \mathrm{Wh} / \mathrm{L}$ was introduced into the reactor.

Either power consumption will be high when UV lamps are used for the process or land area demand will be very large when the photocatalytic process is designed to be powered by the sun. India is a sub-tropical country receiving adequate solar UV radiation around 10 months in a year [41]. As an estimate for the lowest insolation in the year at Tiruppur (in November), $4.3 \mathrm{kWh} / \mathrm{m}^{2} / \mathrm{d}$ can be selected from the respective Gaisma website [42]. Considering the required UV dose of $16.5 \mathrm{kWh} / \mathrm{m}^{3}$ and a minimum solar UV irradiation (5\% of global irradiation) of $0.215 \mathrm{kWh} / \mathrm{m}^{2} /$ day as calculated from the value given above, the area required to treat one $\mathrm{m}^{3}$ of textile dye house effluent within one day would be about $77 \mathrm{~m}^{2}$. This would result in a wastewater layer with a depth as small as $1.3 \mathrm{~cm}$. Without covering the reactor with UV-translucent material, this shallow layer will be completely evaporated within one day preventing wastewater reuse. It has to be pointed out that this large area would only result in a TOC removal by the PCO/PAC hybrid process of not much more than $50 \%$ as can be seen in Figure 9(b). As also other investigations [28] [30] indicated large area demand for solar PCO of textile wastewaters, large volumes of textile wastewater are not recommended to be treated by this solar process.

\section{Conclusion}

Although color was removed by PCO from aqueous RB4 solutions used as simulated wastewater, the mineralisation of RB4 by this process was poor. The addition of chloride and sulfate concentrations found in real textile wastewaters did not deteriorate the efficiency of photocatalytic RB4 degradation. However, the radical scavenger hydrogen carbonate depressed efficiency of PCO as shown by experiments with model wastewater prepared in a tap water matrix. Color as well as TOC removal by PCO was intensified when sorbents (powdered activated carbon or the anion exchange resin Lewatit) were added to the PCO process. It turned out that RB4 was more efficiently adsorbed to PAC and Lewatit when $\mathrm{TiO}_{2}$ was present. This could not be explained by the presented data. Although the anion exchange resin was more efficient in enhancing dye removal by PCO than PAC and although it prevented the process from inhibition by the radical-scavenging hydrogen carbonate, hybridisation of the PCO process with Lewatit anion exchange was no longer efficient, when the Lewatit/ $/ \mathrm{TiO}_{2}$ mixture was reused for several UV irradiation cycles. This might be caused by incomplete photocatalytic regeneration or by oxidative damage of the anion exchange resin. Because of good decolorisation of the real textile industry wastewater by the PCO/Lewatit hybrid process and improved TOC removal by the PCO/PAC hybrid process, it was recommended to use anion exchange as a first stage for color removal and PCO in the presence of PAC for textile wastewater treatment rather than PCO alone. From the experimental data, an area demand for solar PCO hybridised with PAC addition of nearly $80 \mathrm{~m}^{2}$ was calculated for the treatment of $1 \mathrm{~m}^{3}$ of the investigated textile industry effluent within one day. Unfortunately, this will result in a residual TOC concentration of still 370 $\mathrm{mg} / \mathrm{L}$. This huge requirement of area for treatment in a highly industrialised area makes solar PCO unsuitable. On the other hand, it is essential that textile dye house effluents are toxic, which eventually justifies a high investment for their treatment to achieve zero liquid discharge. A feasible option would be the use of UV lamps instead of sunlight. Research on PCO has to be advanced in order to minimize the area demand for the solar PCO process.

\section{Acknowledgements}

The authors gratefully acknowledge the support of Susanne Eggers for TOC analyses. They also express their gratitude to the German Federal Ministry of Education and Research (BMBF) for having funded the Master studies of Preethi Grace Theva Neethi Dhas within the International Postgraduate Studies on Water Technologies (IPSWAT) program, without which this research would not have been possible.

\section{References}

[1] Ghaly, A.E., Ananthashankar, R., Alhattab, M. and Ramakrishnan, V.V. (2014) Production, Characterization and Treatment of Textile Effluents: A Critical Review. Chemical Engineering \& Process Technology, 5, 182. http://omicsonline.org/open-access/production-characterization-and-treatment-of-textile-effluents-a-critical-review-215 7-7048.1000182.pdf 
[2] Correia, V.M., Stephenson, T. and Judd, S.J. (1994) Characterisation of Textile Wastewaters-A Review. Environmental Technology, 15, 917-929. http://dx.doi.org/10.1080/09593339409385500

[3] Akpan, U.G. and Hameed, B.H. (2009) Parameters Affecting the Photocatalytic Degradation of Dyes Using $\mathrm{TiO}_{2-}$ Based Photocatalysts: A Review. Journal of Hazardous Materials, 170, 520-529. http://dx.doi.org/10.1016/j.jhazmat.2009.05.039

[4] Rauf, M.A., Meetani, M.A. and Hisaindee, S. (2011) An Overview on the Photocatalytic Degradation of Azo Dyes in the Presence of $\mathrm{TiO}_{2}$ Doped with Selective Transition Metals. Desalination, 276, 13-27. http://dx.doi.org/10.1016/j.desal.2011.03.071

[5] Pang, Y.L. and Abdullah, A.Z. (2013) Current Status of Textile Industry Wastewater Management and Research Progress in Malaysia: A Review. Clean Soil Air Water, 41, 751-764. http://dx.doi.org/10.1002/clen.201000318

[6] Mondal, S. (2008) Methods of Dye Removal from Dye House Effluent-An Overview. Environmental Engineering Science, 25, 383-396. http://dx.doi.org/10.1089/ees.2007.0049

[7] Mountassir, Y., Benyaich, A., Rezrazi, M., Berçot, L. and Gebrati, L. (2013) Wastewater Effluent Characteristics from Moroccan Textile Industry. Water Science \& Technology, 67, 2791-2799. http://dx.doi.org/10.2166/wst.2013.205

[8] Lotito, A.M., De Sanctis, M., Di Iaconi, C. and Bergna, G. (2014) Textile Wastewater Treatment: Aerobic Granular Sludge vs Activated Sludge Systems. Water Research, 54, 337-346. http://dx.doi.org/10.1016/j.watres.2014.01.055

[9] Brik, M., Chamam, B., Schöberl, P., Braun, R. and Fuchs, W. (2004) Effect of Ozone, Chlorine and Hydrogen Peroxide on the Elimination of Colour in Treated Textile Wastewater by MBR. Water Science \& Technology, 49, $299-303$.

[10] Orhon, D., Dulkadiroğlu, H., Doğruel, S., Kabdaşli, I., Sozen S. and Babuna, F.G. (2002) Ozonation Application in Activated Sludge Systems for a Textile Mill Effluent. Water Science \& Technology, 45, 305-313.

[11] Robinson, T., McMullan, G., Marchant, R. and Nigam, P. (2001) Remediation of Dyes in Textile Effluent: A Critical Review on Current Treatment Technologies with a Proposed Alternative. Bioresource Technology, 77, $247-255$. http://dx.doi.org/10.1016/S0960-8524(00)00080-8

[12] Azbar, N., Yonar, T. and Kestioglu, K. (2004) Comparison of Various Oxidation Processes and Chemical Treatment Methods for COD and Color Removal from a Polyester and Acetate Fiber Dyeing Effluent. Chemosphere, 55, 35-43. http://dx.doi.org/10.1016/j.chemosphere.2003.10.046

[13] McCullagh, C., Skillen, N., Adams, M. and Robertson, P.K.J. (2011) Photocatalytic Reactors for Environmental Remediation: A Review. Journal of Chemical Technology and Biotechnology, 86, 1002-1017. http://dx.doi.org/10.1002/jctb.2650

[14] Gulyas, H. (2014) Solar Heterogeneous Photocatalytic Oxidation for Water and Wastewater Treatment: Problems and Challenges. Journal of Advanced Chemical Engineering, 4, Article ID: 1000108.

http://omicsonline.com/open-access/solar-heterogeneous-photocatalytic-oxidation-for-water-and-wastewater-treatment -problems-and-challenges-2090-4568-4-108.pdf

[15] Ahmed, S., Rasul, M.G., Martens, W.N., Brown, R. and Hashib, M.A. (2011) Advances in Heterogeneous Photocatalytic Degradation of Phenols and Dyes in Wastewater: A Review. Water Air Soil Pollution, 215, 3-29. http://dx.doi.org/10.1007/s11270-010-0456-3

[16] Khataee, A.R. and Kasiri, M.B. (2010) Photocatalytic Degradation of Organic Dyes in the Presence of Nanostructured Titanioum Dioxide: Influence of the Chemical Structure of Dyes. Journal of Molecular Catalysis A: Chemical, 328, 826. http://dx.doi.org/10.1016/j.molcata.2010.05.023

[17] Alahiane, S., Qourzal, S., El Quardi, M., Abaamrane, A. and Assabbane, A. (2014) Factors Influencing the Photocatalytic Degradation of Reactive Yellow 145 by $\mathrm{TiO}_{2}$-Coated Non-Woven Fibers. American Journal of Analytical Chemistry, 5, 445-454. http://dx.doi.org/10.4236/ajac.2014.58053

[18] Chebli, D., Fourcade, F., Brosillon, S., Nacef, S. and Amrane, A. (2010) Supported Photocatalysis as a Pretreatment Prior to Biological Degradation for the Removal of Some Dyes from Aqueous Solutions; Acid Red 183, Biebrich Scarlet, Methyl Red Sodium Salt, Orange II. Journal of Chemical Technology and Biotechnology, 85, 555-563.

[19] Kodom, T., Akpénè, D., Tchakala, I., Gnazou, M.E.D.T., Djaney-Boundjou, G. and Bawa, M.L. (2013) TiO 2 PC500 Coated on Non Woven Paper with $\mathrm{SiO}_{2}$ as a Binder-Assisted Photocatalytic Degradation of Reactive Black 5 in Aqueous Solution. Journal of Water Resource and Protection, 5, 1227-1234. http://dx.doi.org/10.4236/jwarp.2013.512131

[20] Gulyas, H., Stürmer, R. and Hintze, L. (2001) Experiences with Solar Application of Photocatalytic Oxidation for Dye Removal from a Model Textile Industry Wastewater. In: Brebbia, C.A., Ed., Water Pollution VI—Modelling, Measuring and Prediction, WIT Press, Southampton, 153-165.

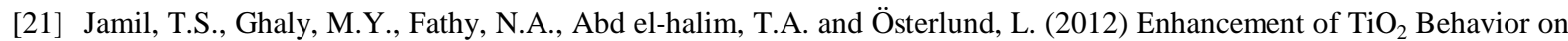
Photocatalytic Oxidation of MO Dye Using $\mathrm{TiO}_{2} / \mathrm{AC}$ under Visible Irradiation and Sunlight Irradiation. Separation and Purification Technology, 98, 270-279. http://dx.doi.org/10.1016/j.seppur.2012.06.018 
[22] Sobana, N. and Swaminathan, M. (2007) Combination Effect of ZnO and Activated Carbon for Solar Assisted Photocatalytic Degradation of Direct Blue 53. Solar Energy Materials Solar Cells, 91, 727-734. http://dx.doi.org/10.1016/j.solmat.2006.12.013

[23] Chun, H. and Yizhong, W. (1999) Decolorization and Biodegradability of Photocatalytic Treated Azo Dyes and Wool Textile Wastewater. Chemosphere, 39, 2107-2115. http://dx.doi.org/10.1016/S0045-6535(99)00118-6

[24] Gebrati, L., Loukili Idrissi, L., Mountassir, Y. and Nejmeddine, A. (2010) Détoxification des effluents d'industrie de textile par photocatalyse. Environmental Technology, 31, 625-632. http://dx.doi.org/10.1080/09593331003592253

[25] Gümüş, D. and Akbal, F. (2011) Photocatalytic Degradation of Textile Dye and Wastewater. Water Air \& Soil Pollution, 216, 117-124. http://dx.doi.org/10.1007/s11270-010-0520-z

[26] Hussein, F.H. (2012) Comparison between Solar and Artificial Photocatalytic Decolorization of Textile Industry Wastewater. International Journal of Photoenergy, 2012, Article ID: 793648. http://dx.doi.org/10.1155/2012/793648 http://www.hindawi.com/journals/ijp/2012/793648/

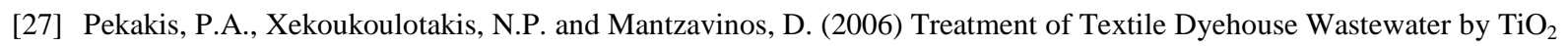
Photocatalysis. Water Research, 40, 1276-1286. http://dx.doi.org/10.1016/j.watres.2006.01.019

[28] Bousselmi, L., Geissen, S.-U. and Schroeder, H. (2004) Textile Wastewater Treatment and Reuse by Solar Catalysis: Results from a Pilot Plant in Tunesia. Water Science \& Technology, 49, 331-337.

[29] Vilar, V.J.P., Pinho, L.X., Pintor, A.M.A. and Boaventura, R.A.R. (2011) Treatment of Textile Wastewaters by SolarDriven Advanced Oxidation Processes. Solar Energy, 85, 1927-1934. http://dx.doi.org/10.1016/j.solener.2011.04.033

[30] Gulyas, H., Jain, H.B., Susanto, A.L., Malekpur, M., Harasiuk, K., Krawczyk, I., Choromanski, P. and Furmanska, M. (2005) Solar Photocatalytic Oxidation of Pretreated Wastewaters: Laboratory Scale Generation of Design Data for Technical-Scale Double-Skin Sheet Reactors. Environmental Technology, 26, 501-514. http://dx.doi.org/10.1080/09593332608618540

[31] Karcher, S., Kornmüller, A. and Jekel, M. (2002) Anion Exchange Resins for Removal of Reactive Dyes from Textile Wastewaters. Water Research, 36, 4717-4724. http://dx.doi.org/10.1016/S0043-1354(02)00195-1

[32] Greluk, M. and Hubicki, Z. (2011) Efficient Removal of Acid Orange 7 Dye from Water Using the Strongly Basic Anion Exchange Resin Amberlite IRA-958. Desalination, 278, 219-226. http://dx.doi.org/10.1016/j.desal.2011.05.024

[33] Liu, C.-H., Wu, J.-S., Chiu, H.-C., Suen, S.-Y. and Chu, K.H. (2007) Removal of Anionic Reactive Dyes from Water Using Anion Exchange Membranes as Adsorbers. Water Research, 41, 1491-1500. http://dx.doi.org/10.1016/j.watres.2007.01.023

[34] Normenausschuss Wasserwesen (1997) Determination of Total Organic Carbon (TOC) (H 3) (in German), DIN EN 1484 (1997-08), German Standard Methods for the Examination of Water, Waste Water and Sludge, DIN Deutsches Institut für Normung e.V., Berlin.

[35] Abdullah, M., Low, G. and Matthews, R. (1990) Effects of Common Inorganic Anions on Rates of Photocatalytic Oxidation of Organic Carbon over Illuminated Titanium Dioxide. Journal of Physical Chemistry, 94, 6820-6825. http://dx.doi.org/10.1021/j100380a051

[36] Bekbölet, M., Boyacioglu, Z. and Özkaraova, B. (1998) The Influence of Solution Matrix on the Photocatalytic Removal of Color from Natural Waters. Water Science \& Technology, 38, 155-162. http://dx.doi.org/10.1016/S0273-1223(98)00577-0

[37] Calza, P. and Pelizzetti, E. (2001) Photocatalytic Transformation of Organic Compounds in the Presence of Inorganic Ions. Pure Applied Chemistry, 73, 1839-1848. http://dx.doi.org/10.1351/pac200173121839

[38] Guillard, C., Puzenat, E., Lachheb, H., Honas, A. and Herrmann, J.-M. (2005) Why Inorganic Salts Decrease the TiO 2 Photocatalytic Efficiency. International Journal of Photoenergy, 7, 1-9. http://dx.doi.org/10.1155/S1110662X05000012

[39] Zhang, W., An, T., Cui, M., Sheng, G. and Fu, J. (2005) Effects of Anions on the Photocatalytic and Photoelectrocatalytic Degradation of Reactive Dye in a Packed-Bed Reactor. Journal of Chemical Technology and Biotechnology, 80, 223-229. http://dx.doi.org/10.1002/jctb.1185

[40] Gulyas, H., Choromanski, P., Muelling, N. and Furmanska, M. (2009) Toward Chemical-Free Reclamation of Biologically Pretreated Greywater: Solar Photocatalytic Oxidation with Powdered Activated Carbon. Journal of Cleaner Production, 17, 1223-1227. http://dx.doi.org/10.1016/j.jclepro.2009.03.008

[41] Shanmuga Priya, S., Premalatha, M. and Anantharaman, N. (2008) Solar Photocatalytic Treatment of Phenolic Wastewater-Potential, Challenges and Opportunities. ARPN Journal of Engineering and Applied Sciences, 3, 36-41. http://www.arpnjournals.com/jeas/research_papers/rp_2008/jeas_1208_141.pdf

[42] GAISMA (Without Date) Tiruppur, India—Solar Energy and Surface Meteorology. http://www.gaisma.com/en/location/tiruppur.html 